\title{
Social networks and parental behavior in the intergenerational transmission of religion
}

\author{
Eleonora Patacchini \\ Department of Economics, Cornell University, Sapienza University of Rome, and EIEF \\ Yves ZeNOU \\ Department of Economics, Monash University and IFN
}

\begin{abstract}
We analyze the intergenerational transmission of the strength of religion focusing on the interplay between family and social influences. We find that parental investment in transmitting religious values and peers' religiousity are complements. The relative importance of these socialization factors depends on the religiosity of the parents.
\end{abstract}

KEYWORDS. Religion, cultural transmission, social networks.

JEL CLASSIFICATION. A14, D85, Z12.

\section{INTRODUCTION}

The past few years have witnessed substantial progress in our understanding of how religious factors influence economic and demographic factors including education, female employment, fertility, and union formation and dissolution (Lehrer (2008)). The economics of religion applies socioeconomic theory and methods to explain the religious behavioral patterns of individuals, groups, or cultures and the social consequences of such behavior. ${ }^{1}$ One particular interesting topic is the study of the transmission of religion across generations. Parents are passing on religious knowledge and attitudes to their children (Clark and Worthington (1987), Hayes and Pittelkow (1993), Hoge, Petrillo, and Smith (1982), Ozorak (1989), Thomson, McLanahan, and Curtin (1992)). The more intensive is the parents' practice (for example, church attendance), the more they expose their kids to religious practice, and hence invest in the children's "religious capital" and transmit religious attitudes to the next generation. The aim of the present paper is to study the transmission of religious intensity by highlighting the

Eleonora Patacchini: ep454@cornell.edu

Yves Zenou: yves . zenou@monash . edu

We are grateful to a co-editor and two anonymous referees for helpful comments. We also thank Alberto Bisin, Luigi Guiso, Giacomo De Giorgi, the participants of the MOVE Workshop on Social Economics, Barcelona, April 20-21, 2012, and of the Conference on the Economics of Interactions and Culture, Rome, April 27-28, 2012, for constructive comments. We finally thank Tiziano Arduini for excellent research assistance.

${ }^{1} \mathrm{~A}$ comprehensive review of the literature is presented in Iannaccone (1998).

Copyright () 2016 Eleonora Patacchini and Yves Zenou. Licensed under the Creative Commons AttributionNonCommercial License 3.0. Available at http: //www . qeconomics . org.

DOI: $10.3982 / Q E 506$ 
trade-off faced by parents between the time they devote to religious activities and the religious exposure of their children, that is, peer effects.

To be more precise, we develop a theoretical framework in which parents' involvement in religious activities as well as the peers' influence on the children are the key ingredients in explaining religious outcomes. Indeed, based on some works on anthropology and sociology (see, in particular, Boyd and Richerson (1985) and Cavalli-Sforza and Feldman (1981)), the literature initiated by Bisin and Verdier $(2000,2001)$ argues that the transmission of a particular trait (religion, ethnicity, social status, etc.) is the outcome of a socialization inside and outside the family (like, e.g., peers and role models). These two types of socialization are cultural substitutes (complements) if parents have less (more) incentive to socialize their children, the more widely dominant are their values in the population. In our model, there are two different types of people: more religious and less religious. ${ }^{2}$ The transmission of these traits is costly since parents have to give up leisure, but is also rewarding since it positively influences the chances of their children being like them (more religious for the more religious parents and less religious for the less religious parents). Altruistic parents, who can either be more or less religious, have therefore to decide how often they attend a religious service with their children.

There are two main differences with the standard approach of cultural transmission à la Bisin and Verdier (2000, 2001) and Bisin, Topa, and Verdier (2004). First, we do not consider two types of religion (say Protestant and Catholic), and thus the transmission of a particular religion, but two types of intensity of religion and thus the transmission of this intensity within the same religious group. In other words, we analyze if the more religious parents have more religious kids and if the less religious parents do not. Second, and this is one of our main contributions, contrary to Bisin and Verdier (and the subsequent literature of cultural transmission; see our discussion below) where peer effects are conceived as an average intragroup externality with arbitrary group boundaries and at a quite aggregate level (residential neighborhood, state, or even country level), here peers will be defined by the smallest unit of analysis for peer effects, that is, the dyada two-person group. The collection of active bilateral influences or dyads will constitute a social network. ${ }^{3}$

In the theoretical model, we show that the choice of parents' socialization effort (i.e., how much time they spend transmitting their trait) involves a trade-off between the direct costs of socialization and the long-run expected benefits, which consist of a better chance of having a child with the same religion intensity. If the marginal cost of socialization increases with the fraction of more religious (less religious) friends, then cultural substitution prevails, that is, the higher is the percentage of the child's more religious (less religious) friends, the less the more religious (less religious) parents put effort into transmitting their trait. On the other hand, if it decreases with the fraction of more religious (less religious) friends and the benefits from socialization is not too high, then

\footnotetext{
${ }^{2}$ Observe that we define these two types (more religious and less religious) on the basis of self-reported information on participation in/attendance at church activities. See Section 4.2 for the description of our data.

${ }^{3}$ The economics of networks is a growing field; see Jackson (2014) for an overview.
} 
cultural complementarity is at work, meaning that the higher is the fraction of the child's more religious friends, the more religious parents put effort into transmitting their trait.

We then test these predictions using data from the National Longitudinal Survey of Adolescent Health (AddHealth). This data set has been extensively used for its unique information on friendship networks. It collects data on students in grades 7-12 from a nationally representative sample of roughly 130 private and public schools in years 1994-1995. The information on friendship networks is based on actual friends nominations during the school years. Indeed, pupils were asked to identify their best friends from a school roster (up to five males and five females). The questionnaire contains also questions about religion. To the best of our knowledge, this information has not been used yet.

We test how the religion strength of the friends of a child affects the parent's decision to socialize his/her child to his/her own religion strength. A major econometric issue arises from the fact that the choice of friends may not be exogenous. We address this issue using an identification strategy that has previously been used to identify peer effects in other contexts (e.g., Bifulco, Fletcher, and Ross (2011), Lavy and Schlosser (2011), Hoxby (2000)).The idea is to treat the composition of students in a given grade within a school as quasi-random and to isolate this quasi-random variation in the friendship network formation process. We use the fraction of religious students of the same gender, religious affiliation, and ethnic group in the same grade and school as an instrument for the individual (children) fraction of religious friends.

We find that, for religious parents, the higher is the fraction of religious peers of the child, the more parents put effort into transmitting their religiosity, indicating cultural complementarity. For the less religious parents, the lower is the fraction of religious peers of the child, the less the parents go to a religious service with their child, also indicating cultural complementarity since the transmission is about the less religious trait.

The rest of the paper unfolds as follows. In the next section, we highlight our contribution by summarizing the relevant related literature. In Section 3, we present our theoretical model. In Section 4, we describe the empirical model and the data, and tackle the econometric issues. Section 5 gives and interprets the results. Section 6 discusses some policy implications of this paper, while Section 7 concludes.

\section{Related literature}

As stated in the Introduction, there is an important literature on cultural transmission initiated by the seminal papers of Bisin and Verdier $(2000,2001) .{ }^{4}$ In this literature, cultural transmission is conceptualized as the result of interactions between purposeful socialization decisions inside the family (direct vertical socialization) and other socialization processes like social imitation and learning that govern identity formation (oblique and horizontal socialization). Cultural traits are endogenous in this context. Allowing for interesting socioeconomic effects interacting with the socialization choices of parents, the basic cultural transmission model of Bisin and Verdier has been applied to several

\footnotetext{
${ }^{4}$ For an overview, see Bisin and Verdier (2011).
} 
different environments and cultural traits and social norms of behavior, from preferences for social status (Bisin and Verdier (1998)), to corruption (Hauk and Sáez-Martí (2002)), hold up problems (Olcina and Penarrubia (2004)), development and social capital (Francois (2002)), intergenerational altruism (Jellal and Wolff (2002)), labor market discrimination and work ethics (Sáez-Martí and Zenou (2012)), globalization and cultural identities (Olivier, Thoenig, and Verdier (2008)), education (Botticini and Eckstein (2005, 2007), Patacchini and Zenou (2011)), and identity (Bisin, Patacchini, Verdier, and Zenou (2011a)).

As in the present paper, there are some studies that have analyzed the transmission of religion. Azzi and Ehrenberg (1975) and Neuman (1986) and Iannaccone (1990) have suggested following the human capital approach to study the accumulation of an individual's religious capital. The accumulation of an individual's religious capital starts at childhood when the parents pass on religious knowledge and attitudes to their children, and then continues with religious practices at school, at church, and in the neighborhood where the child lives. A positive empirical relationship between the intensity of exposure to religious conduct during childhood and the individual's current religiosity has been documented in the literature (e.g., Brañas Garza and Neuman (2007), Hayes and Pittelkow (1993), Hoge, Petrillo, and Smith (1982), Ozorak (1989), Thomson, McLanahan, and Curtin (1992)). There are also studies using the Bisin-Verdier framework to study the transmission of religion traits from parents to children. Cohen-Zada (2006) finds for the United States that the demand for private religious schooling decreases with the share of the religious minority in the population, which is in accordance with a cultural substitution mechanism. Bisin, Topa, and Verdier (2004), using the General Social Survey (GSS) survey data for the United States over the period 19721996, estimate for religious traits the structural parameters of the model of marriage and child socialization in Bisin and Verdier (2000). They find that observed intermarriage and socialization rates are consistent with Protestants, Catholics and Jews having a strong preference for children who identify with their parents' own religious beliefs, and taking costly decisions to influence their children's religious beliefs. The estimated "relative intolerance" parameters are high and asymmetric across religious traits, suggesting an interestingly rich representation of cultural distance. More recently, using data from 32 countries (included in the International Social Survey Program: Religion II (ISSP), 1998), Bar-El, Garcia-Muñoz, Neuman, and Tobol (2013) study the transmission of religious norms and, in particular, on the religious taste of children. They find that (i) direct religious socialization efforts of one generation have a negative effect on secularization within the next generation, (ii) there is an inverse U-shaped relationship between oblique socialization by the community (as measured by the diversity of religions in the country of residence) and secularization, and (iii) the two types of socialization are complements in producing religiosity of the next generation.

Our paper is related to this literature since it studies a similar question: how is religion transmitted from one generation to another? However, it is also quite different since we focus on the transmission of the strength of religion and use a network approach. This allows us to define in a much more precise way the quality of the "neighborhood" where the child lives. Instead of using aggregate measures of neighborhoods, which in 
some papers are at the state or even country levels, we use the friends each student has nominated. In other words, the fraction of religious friends each individual has will be our measure of oblique and horizontal socialization.

\section{THEORETICAL MODEL}

\subsection{General model}

As in Bisin and Verdier $(2000,2001)$, the transmission of religion is modeled as a mechanism of interacting socialization inside the family (vertical socialization) with socialization outside the family (oblique socialization) via imitation and learning from peers. As stated above, the peers are defined as friends of each individual in a given network.

Reference group We would like to define the reference group of each student $i$. We denote by $q_{i}$ the fraction of individual $i$ 's friends who are "more religious" (type $a$ ) and denote by $1-q_{i}$ the fraction of those who are "less religious" (type $b$ ). We assume that agents have initial endowments of religiosity as children (due to their background) so that some children are more religious (type $a$ ) than others (type $b$ ). This is taken as given. The aim of the model is then to examine if the children will confirm or reject their religiosity when adults on the basis of the socialization effort of the parents (into more or less religiosity) and the peer religiosity $q_{i}$. This is what we study now.

Intergenerational transmission of religion Let us now explain how the religion transmission works. We denote by $\pi^{r r}$ the probability that a parent with religious intensity $r \in\{a, b\}$ has a child who adopts religious intensity $r \in\{a, b\}$ when adult. We also denote by $e^{r} \in[0,1]$ the "religious attendance with parent of type $r$," with higher values corresponding to attending more often. In other words, the higher is $e^{r}$, the more often parents of type $r$ attend a religious service with their children.

As in Bisin and Verdier $(2000,2001)$, we assume that for the more (resp. less) religious parents, transmission of own religious strength will be successful with a probability equal to $e^{r}$ (resp. $1-e^{r}$ ). This is the vertical transmission of religion (i.e., from the parent to the child). If transmission is not successful, then the horizontal transmission (i.e., from individuals in the network to the child) will play a major role and, in that case, the child will either be more or less religious and the probability of becoming more religious will be identical to the proportion of more religious friends $q_{i}$. We obtain the transition probabilities

$$
\begin{aligned}
& \pi^{a a}=e^{a}+\left(1-e^{a}\right) q_{i}, \\
& \pi^{a b}=\left(1-e^{a}\right)\left(1-q_{i}\right), \\
& \pi^{b b}=1-e^{b}+e^{b}\left(1-q_{i}\right), \\
& \pi^{b a}=e^{b} q_{i} .
\end{aligned}
$$

Let us interpret equation (1). The child of a more religious parent (type $a$ parent) will also be him/herself more religious if either his/her parents' religion transmission is successful (probability $e^{a}$ ) or if the parent fails to transmit his/her trait (probability $1-e^{a}$ ) 
and the child picks up the religious trait from his/her direct friends (probability $q_{i}$ ). In other words, if 10 percent of $i$ 's friends are very religious (i.e., $q_{i}=0.10$ ), then if $i$ 's parent fails in transmitting religion $a, i$ has a 10 percent chance of becoming of type $a$. Equation (2) gives the probability that a child of type $a$ parents adopts religion intensity $b$ : it is because both the parents and the friends were unsuccessful in transmitting religion strength $a$ to the child. For type $b$ parents (equations (3) and (4)), the interpretation is slightly different since the more often a less religious parent goes to a religious service with his/her child, the less likely the child is to become like his/her parent (i.e., less religious).

Observe that if we interpret equations (1)-(4) narrowly in the sense that $e^{r}$ measures just the frequency of religious attendance, then the model has the odd feature that peers can affect kids of type $a$ parents only if the parent goes to church infrequently and that peers can affect kids of type $b$ parents only if the parent goes to church frequently; that is, somehow frequent church visits preclude peer influences for type $a$ families but infrequent church visits preclude peer influences for type $b$ families. To address this issue, we interpret here the effort $e^{r}$ in a broader way so that it captures more than just frequency of religious visits. In particular, for the less religious families (type $b$ ), a low $e^{b}$ will mean that the parents do other stuff with their kids to socialize them to become less religious.

Observe also that, in this model, when the parent $r$ decides how often he/she will go to a religious service with his/her child (i.e., $e^{r}$ ), given his/her initial endowment of religiosity, the child has not yet confirmed or rejected his/her religiosity. He/she will make this decision when adult.

Parents' expected utility Let $V^{r r}$ denote the utility a type $r$ parent derives from having a child of type $r \in\{a, b\}$. We assume that $V^{r r}>V^{r r^{\prime}}$ if $r \neq r^{\prime}$. Indeed, we assume that altruism motivates parents to exert effort to socialize their children. As in Bisin and Verdier (2000, 2001), this altruism, however, is assumed to be "paternalistic" in the sense that parents wish to transmit their own trait, and do not just internalize their children's preferences or some measure of their success. More precisely, parents are altruistic toward their children and want to socialize them to their own specific cultural model.

As a result, the expected utility of a parent of type $r \in\{a, b\}, r^{\prime} \in\{a, b\}, r \neq r^{\prime}$, is given by

$$
W^{r}=\alpha^{r} e^{r}+\pi^{r r} V^{r r}+\pi^{r r^{\prime}} V^{r r^{\prime}}-C^{r}\left(e^{r}, q_{i}\right)
$$

where $\alpha^{r}$ (for $r=a, b$ ) are the observable characteristics of parent $r$ (i.e., gender, race, education, etc.) and $C^{r}\left(e^{r}, q_{i}\right)$ is the cost of socialization, which depends on both the socialization effort and the fraction of the child's religious friends. As reflected by $C^{r}\left(e^{r}, q_{i}\right)$, we assume that the cost function is different for type $a$ and $b$ parents. We also as- 
sume that the cost function is increased and convex in effort, that is, $C_{e}^{r \prime}\left(e^{r}, q_{i}\right)>0$ and $C_{e e}^{r \prime \prime}\left(e^{r}, q_{i}\right) \geq 0 .{ }^{5}$ For a parent of type $a$, we have

$$
W^{a}=\alpha^{a} e^{a}+\left[e^{a}+\left(1-e^{a}\right) q_{i}\right] V^{a a}+\left(1-e^{a}\right)\left(1-q_{i}\right) V^{a b}-C^{a}\left(e^{a}, q_{i}\right),
$$

while for a parent of type $b$,

$$
W^{b}=\alpha^{b} e^{b}+\left[1-e^{b}+e^{b}\left(1-q_{i}\right)\right] V^{b b}+e^{b} q_{i} V^{b a}-C^{b}\left(e^{b}, q_{i}\right) .
$$

Parents' optimal socialization effort Let us now determine $e^{r}$, the time spent going to a religious service with his/her child $i$ for a parent of type $r$. Denote $\Delta V^{a} \equiv V^{a a}-V^{a b}>0$ and $\Delta V^{b} \equiv V^{b b}-V^{b a}>0$. The first-order condition for parent of type $a$ is

$$
C_{e}^{a \prime}\left(e^{a}, q_{i}\right)=\alpha^{a}+\left(1-q_{i}\right) \Delta V^{a} .
$$

Similarly, for type $b$ parents, we have

$$
C_{e}^{b \prime}\left(e^{b}, q_{i}\right)=\alpha^{b}-q_{i} \Delta V^{b} .
$$

Denote these optimal efforts as $e^{r *} \equiv e^{r *}\left(q_{i}\right)$ for $r \in\{a, b\}$.

\section{Proposition 1.}

(i) Consider type a parents. Assume that

$$
\alpha^{a}>C_{e}^{a \prime}\left(0, q_{i}\right) \quad \forall q_{i} \in[0,1] .
$$

Then there exists a unique and interior $e^{a *} \equiv e^{a *}\left(q_{i}\right)$.

(ii) Consider now type b parents.

(ii1) Assume that

$$
\alpha^{b}>C_{e}^{b^{\prime}}\left(0, q_{i}\right)+\Delta V^{b} \quad \forall q_{i} \in[0,1] .
$$

Then there exists a unique and interior $e^{b *} \equiv e^{b *}\left(q_{i}\right)$.

(ii2) Assume that $\alpha^{b}<0$. Then parents of type $b$ will exert no effort, that is, $e^{b *}=0$.

Proposition 1 characterizes the solution $e^{r *}$ and shows the condition under which it is unique and interior. For type $a$ (more religious) parents, it is quite natural to assume that $\alpha^{a}>0$ since $\alpha^{a}$ captures the marginal utility of a parent to put effort into going to church, independent of the peers and the impact on the socialization of the child. For parents of type $b$ (less religious), it is less obvious and this is why, in Proposition 1 , we consider the cases of both $\alpha^{b}>0$ and $\alpha^{b}<0$. The latter is relatively easy to

\footnotetext{
${ }^{5}$ In terms of notations, we have

$$
C_{e}^{r \prime}\left(e^{r}, q_{i}\right) \equiv \frac{\partial C^{r}\left(e^{r}, q_{i}\right)}{\partial e^{r}} \quad \text { and } \quad C_{e e}^{r \prime \prime}\left(e^{r}, q_{i}\right) \equiv \frac{\partial^{2} C^{r}\left(e^{r}, q_{i}\right)}{\partial\left(e^{r}\right)^{2}} .
$$
}


justify, as parents of type $b$ do not enjoy going to church, even if it is with their kids. In that case (part (ii2) of Proposition 1), quite naturally, their optimal effort is zero, that is, $e^{b *}=0$, which means that less religious parents minimize church-going activities if they are costly. Consider now the case when $\alpha^{b}>0$. In part (iil) of Proposition 1, we show that if $\alpha^{b}$ is high enough, then less religious parents will put a positive effort into socializing their kids to religion. ${ }^{6}$ Let us now justify why $\alpha^{b}>0$ makes sense even for less religious parents. If we consider $W^{b}$, the utility of parents of type $b$, defined in (6), then the assumption $\alpha^{b}>0$ means that parents of type $b$ derive positive marginal utility from going to church with their children. In other words, this means that (less religious) parents of type $b$ enjoy spending time with their kids, even if it is going to a religious service. There are two ways to justify the assumption $\alpha^{b}>0$, which implies that $\alpha^{b} e^{b} \geq 0$ in (6). First, as stated above, we interpret $e^{b}$ in a broader way so that it captures more than just frequency of religious visits. As a result, for the less religious families (type $b$ ), a positive but low $\alpha^{b} e^{b}$ would mean that the parents do other stuff with their kids to socialize them to become less religious. Second, $\alpha^{b} e^{b} \geq 0$ could also mean that even if parents want their kids to be less religious, they still enjoy going to a religious service together since this means spending more time with their kids. There are clearly many other activities (playing games, playing in the park, doing outdoor activities, being involved with sports) that less religious parents could do with their kids that would not entail the cost of making their kids more likely to acquire a trait (being more religious) that the parents dislike. What we assume here is that there may be some social pressure from other parents to bring kids to a religious service and that is why the less religious parents still obtain some positive utility from going to a religious service with their kids. In this interpretation, going to a religious service with kids is a way through which parents conform to the group's social norm, and thus enjoy some utility from doing it.

Let us now focus on interior solutions only.

Proposition 2. Assume (9) and (10). Then, for all parents of type $r=a, b$, the following statements hold:

(i) If $C_{e q}^{r \prime \prime}\left(e^{r}, q_{i}\right)>-\Delta V^{r}$, cultural substitution prevails, that is, $\frac{\partial e^{r *}}{\partial q_{i}}<0$.

(ii) If $C_{e q}^{r \prime \prime}\left(e^{r}, q_{i}\right)<-\Delta V^{r}$, cultural complementarity prevails, that is, $\frac{\partial e^{r *}}{\partial q_{i}}>0$.

The first-order conditions (7) show that for more religious parents, the choice of $e^{a}$ involves a trade-off between the direct marginal cost $C_{e}^{a \prime}\left(e^{a}, q_{i}\right)$ and the marginal benefits, which consist of a better chance of having a child with the same religion intensity $a$. This is not true for less religious parents. For the latter, both of these factors are costs, working against going to religious services. Indeed, when going to religious services, less religious parents incur a direct marginal cost $C_{e}^{b \prime}\left(e^{b}, q_{i}\right)$ and suffer an indirect cost because their child is less likely to have their religious intensity. The less religious parents

\footnotetext{
${ }^{6}$ Observe that the condition $\alpha^{b}>C_{e}^{b \prime}\left(0, q_{i}\right)+\Delta V^{b}$ in part (iil) of Proposition 1 is a sufficient condition. The exact condition is $\alpha^{b}>C_{e}^{b \prime}\left(0, q_{i}\right)+q_{i} \Delta V^{b}$. Similarly, the condition $\alpha^{a}>C_{e}^{a \prime}\left(0, q_{i}\right)$ in part (i) of Proposition 1 is a sufficient condition. The exact condition is $\alpha^{a}+\left(1-q_{i}\right) \Delta V^{a}>C_{e}^{a \prime}\left(0, q_{i}\right)$.
} 
thus trade off both of these costs against the positive $\alpha^{b}$ term of spending time with their children.

Interestingly, the predictions of the impact of $q_{i}$, the fraction of more religious friends of student $i$, on parents' religious activity with the child $e^{r}$ is the same whatever the religiosity of the parent. If $C_{e q}^{r \prime \prime}\left(e^{r}, q_{i}\right) \geq 0$, which means that the higher is $q_{i}$, the higher is the marginal cost of socializing the child, then, since $\Delta V^{r}>0$, cultural substitutability always prevails, that is, the higher is $q_{i}$, the less the (more or less) religious parents put effort into transmitting their trait, because it is more costly at the margin to transmit the (more or less) religious trait. Observe that assuming $C_{e q}^{r \prime \prime}\left(e^{r}, q_{i}\right)<0$, so that it is less costly to transmit the religious trait when there are more religious children around, does not necessarily lead to cultural complementarity. It has to be that the gain of transmitting the religious trait, $\Delta V^{r}$, is not too high and/or the reduction in marginal cost is large enough. This is because when the fraction of religious kids in the child's environment increases, the marginal benefits from a successful transmission of the religious trait cannot be too large for the parents to increase their effort; otherwise parents will let the neighborhood takes care of their child's transmission of the religious trait.

\subsection{Cost functional form}

Equations (7) and (8) give the equilibrium effort of parents of each type $r=a, b$. Let us now assume that the cost function $C^{r}\left(e^{r}, q_{i}\right)$ can be written as

$$
C^{r}\left(e^{r}, q_{i}\right)=\frac{1}{2}\left(e^{r}\right)^{2}+\delta^{r} e^{r}\left(1-q_{i}\right)
$$

where $\delta^{r}$ could be positive or negative. For parents of type $a$, the first-order condition (7) can be written as

$$
e^{a}=\gamma^{a} q_{i}+X^{a}
$$

where $\gamma^{a} \equiv \delta^{a}-\Delta V^{a}$ and $X^{a} \equiv \alpha^{a}-\gamma^{a}$. For parents of type $b$, the first-order condition (8) can be written as

$$
e^{b}=\gamma^{b} q_{i}+X^{b}
$$

where $\gamma^{b} \equiv \delta^{b}-\Delta V^{b}$ and $X^{b} \equiv \alpha^{b}-\delta$. Let us only focus on interior solutions. We have the following result. ${ }^{7}$

Corollary 1. Assume that the cost function is given by (11).

(i) For parents of type a, if $\alpha^{a}>\delta^{a}$, then there exists a unique and interior $e^{a *} \equiv e^{a *}\left(q_{i}\right)$.

(ii) For parents of type $b$, if $\alpha^{b}>\delta^{b}+\Delta V^{b}$, then there exists a unique and interior $e^{b *} \equiv$ $e^{b *}\left(q_{i}\right)$.

\footnotetext{
${ }^{7}$ If $\delta^{r} \geq 0$, then $C_{e}^{r \prime}\left(e^{r}, q_{i}\right)>0$. If $\delta^{r}<0$, then assume $e^{r}+\delta>0$. This guarantees that $C_{e}^{r \prime}\left(e^{r}, q_{i}\right)>0$. It is easily verified that for the optimal $e^{r *} \equiv e^{r *}\left(q_{i}\right)$, assuming $\alpha^{a}>\delta^{a}$ guarantees that $e^{a *}+\delta^{a}>0$ and assuming $\alpha^{b}>\delta^{b}+\Delta V^{b}$ guarantees that $e^{b *}+\delta^{b}>0$.
} 
We can now obtain our second result.

Corollary 2. Assume that the cost function is given by (11). Assume that $\alpha^{a}>\delta$ and $\alpha^{b}>\delta+\Delta V^{b}$. Then, for all parents of type $r=a, b$, the following statements hold:

(i) If $\delta^{r}<\Delta V^{r}$, cultural substitution prevails, that is, $\frac{\partial e^{r *}}{\partial q_{i}}<0$.

(ii) If $\delta^{r}>\Delta V^{r}$, cultural complementarity prevails, that is, $\frac{\partial e^{r *}}{\partial q_{i}}>0$.

\subsection{Implications for the dynamics of the model}

Proposition 2 and Corollary 1 show that whether peer religiosity is a substitute or complement to parental socialization has crucial implications for the dynamics of cultural traits over time. Consider our two traits, more religious and less religious. Bisin and Verdier $(2000,2001)$ have shown the following results: ${ }^{8}$

(i) Under cultural substitution, there exists a unique stable steady-state equilibrium at which there is cultural heterogeneity in the society, with a representation of both very religious and less religious individuals. In other words, if there is cultural substitutability, the only stable steady-state equilibrium is such that cultural heterogeneity always prevails, that is, $0<q_{i}^{*}<1$.

(ii) Under cultural complementarity, there are two possible stable steady-state equilibria with cultural homogeneity in the society: either all individuals become very religious or less religious. In other words, if there is cultural complementarity, the only stable steady-state equilibrium is such that cultural assimilation always prevails, that is, either $q_{i}^{*}=0$ or $q_{i}^{*}=1$.

The intuition is as follows. Consider cultural substitutability. In that case, $q_{i}=0$ (only less religious agents in the population) cannot be a stable equilibrium because if a positive population shock hits the system at $q_{i}=0$, the fraction of the population of type $a$ begins to grow because more religious parents put more effort into transmitting their trait due to cultural substitution, and will continue to do so until this growth reaches its maximum rate at $0<q_{i}^{*}<1$. The case is the same for a negative shock at the point $q_{i}=1$. If, however, a positive shock hits the system at $0<q_{i}^{*}<1$, then there is negative growth in the population (because of cultural substitutability) and the system returns to the point $0<q_{i}^{*}<1$. Similarly a negative shock at this point would cause the population growth rate to become positive, which would once again bring the population size back to $0<q_{i}^{*}<1$. With the same reasoning, it is straightforward to understand why, under cultural complementarity, the only stable steady-state equilibria are either $q_{i}^{*}=0$ or $q_{i}^{*}=1$.

\footnotetext{
${ }^{8}$ Observe that in the Bisin-Verdier model the peer effect $q_{i}$ comes from uniform random matching at the level of the whole group. Here, we adopt a network approach so that $q_{i}$ is a frequency at the level of the neighborhood of a particular individual (node) $i$ (not a group average). From this, it follows that the true cultural dynamics cannot be reduced to a single dimension (as in Bisin-Verdier) but would have to be considered on the full social network nodes of the sample. This is clearly untractable. A mean field approximation dynamics of religiosity should, however, give the same insights as the dynamics described by the Bisin-Verdier model.
} 


\section{EMPIRICAL ANALYSis}

\subsection{Empirical model}

The aim of our empirical analysis is to test Proposition 2 or, more exactly, Corollary 1, that is the influence of local environment (quality of the peers) on the parents' decision of spending time with their children transmitting religion values. More precisely, we would like to test the first-order conditions from the theoretical model (12) and (13). It should be clear that (12) and (13) lead to the same empirical counterpart, which, for $r=a, b$, is

$$
e_{i, t}^{r}=\gamma q_{i, t}+\sum_{m=1}^{M} \beta_{m}^{r} x_{m, i, t}^{r}+\varepsilon_{i, t},
$$

where $q_{i, t}$ captures the religiosity of the friends of individual $i$ at time $t$. Furthermore, $e_{i, t}^{r}$ denotes the religious attendance of child $i$ with parent $r$ at time $t ; x_{m, i, t}^{r}$ (for $m=$ $1, \ldots, M)$ is a set of $M$ control variables at the parent, child, household, and area level at time $t$, accounting for differences in socioeconomic characteristics between parents, children, families, and neighborhoods (listed in Table A1 in Appendix A, available in a supplementary file on the journal website, http://qeconomics.org/supp/506/ supplement.pdf); $\varepsilon_{i, t}$ is a white noise error term.

A test of this equation will allow us to evaluate the prediction of the theoretical model. A $\gamma$ significantly different from zero will indicate either cultural substitution (if negative) or cultural complementarity (if positive). The sign of $\gamma$ will therefore provide information on the form of the trade-off between the composition of the friendship network and the parental investment in terms of religion transmission.

\subsection{Data and definition of variables}

Our empirical analysis is based on data from the National Longitudinal Survey of Adolescent Health (AddHealth). ${ }^{9}$ The AddHealth survey has been designed to study the impact of the social environment (i.e., friends, family, neighborhood, and school) on adolescents' behavior in the United States by collecting data on students in grades 7-12 from a nationally representative sample of roughly 130 private and public schools in the years 1994-1995. Every pupil attending the sampled schools on the interview day is asked to compile a questionnaire (in-school data) containing questions on respondents' demographic and behavioral characteristics, education, family background, and friendship. This sample contains information on roughly 90,000 students. A subset of adolescents

\footnotetext{
${ }^{9}$ This research uses data from AddHealth, a program project directed by Kathleen Mullan Harris and designed by J. Richard Udry, Peter S. Bearman, and Kathleen Mullan Harris at the University of North Carolina at Chapel Hill, and funded by Grant P01-HD31921 from the Eunice Kennedy Shriver National Institute of Child Health and Human Development, with cooperative funding from 23 other federal agencies and foundations. Special acknowledgment is due Ronald R. Rindfuss and Barbara Entwisle for assistance in the original design. Information on how to obtain the AddHealth data files is available on the Add Health website (http://www.cpc.unc.edu/addhealth). No direct support was received from Grant P01-HD31921 for this analysis.
} 
selected from the rosters of the sampled schools, about 20,000 individuals, is then asked to compile a longer questionnaire containing more sensitive individual and household information (in-home and parental data). One of the most interesting aspects of the AddHealth data is the information on friendship networks, which is based on actual friends nominations during the school years. Indeed, pupils were asked to identify their best friends from a school roster (up to five males and five females). ${ }^{10}$ As a result, one can reconstruct the whole geometric structure of the friendship networks. Such detailed information on social interaction patterns allows us to measure the relevant local community, that is, the students who actually interact with each other, much more precisely than in previous studies. Given that friendship relationships are typically reciprocal, we consider that a link exists between two friends if at least one of the two individuals has identified the other as his/her best friend. For each school, we keep track of all the individuals who directly interact with a given student. By matching the identification numbers of the friendship nominations to the respondents' identification numbers, one can also obtain information on the characteristics of the nominated friends. ${ }^{11}$

The AddHealth questionnaire contains various questions about religion. In particular, each student is asked whether he/she has gone to a religious service or a churchrelated event in the last four weeks with his/her mother and with his/her father (separately). This is unique information that allows us to derive a proxy for parental investment in transmitting their religious trait, $e^{r}$. We use a dichotomous variable (labeled as "religious attendance with parents") that takes a value of 1 if the child declares having/not having gone to a religious service or a church-related event in the last four weeks with at least one parent and a value of 0 otherwise.

The intensity of religiosity of the local community (friends) of each individual $i$, $q_{i}(g)$, is derived from the information on nominated friends in network $g$. We label this variable as "peer religiosity." We use the question, "How often have you gone to religious services in the past year?," coded as $4=$ once a week or more, $3=$ less than once a week, but at least once a month, $2=$ less than once a month, $1=$ never, and $0=$ if the individual declares not having a religion. Peer religiosity is the average strength of religion of the friends of each student $i$, which is obtained by taking the average value of the answers to this question. Observe that this measure is independent of the religion of the friends of $i$ since, for example, a very religious Jew can obviously affect a Catholic student if they are friends.

We distinguish between more religious parents and less religious parents using the response to the question, "How often have you gone to religious services in the past year?," coded as $4=$ once a week or more, $3=$ less than once a week, but at least once a month, 2 = less than once a month, $1=$ never, and $0=$ if the individual declares not

\footnotetext{
${ }^{10}$ The limit in the number of nominations is not binding (even by gender). Less than $0.1 \%$ of the students in our sample show a list of 10 best friends; less than $2 \%$ of the students nominate 5 female friends or 5 male friends ( $1.8 \%$ and $1.9 \%$, respectively).

${ }^{11}$ The other existing surveys that report friends' nomination are ego networks, that is, the respondent lists his/her contacts and some basic characteristics of them (such as gender, education, employment status). Detailed information about nominated contacts is typically not available.
} 
having a religion. ${ }^{12}$ We define as more religious parents, that is, $r=a$, those who have answered 3 or 4 to the question above, while less religious parents, that is, $r=b$, are those who have answered 1 or 2 to the question above. ${ }^{13}$ We exclude parents who declare not having any religion. ${ }^{14}$

Our final sample of in-home students (and friends) that can be tracked into networks consists of about 9500 individuals distributed over 132 schools. The large reduction in sample size with respect to the original sample is due to the fact that the information on religion behavior is only asked to a subsample of students (in the in-home questionnaire) and to the nomination information. Indeed, roughly $20 \%$ of the students do not nominate any friends and another $20 \%$ cannot be correctly linked (for example, because the identification code is missing or misreported). Table A1 in Appendix A provides precise definitions and descriptive statistics of the variables used in our study for the entire sample. Table A2 distinguishes between more religious and less religious parents. Among the individuals selected in our sample, roughly $60 \%$ have more religious parents and $40 \%$ have less religious parents. About $64 \%$ of children of more religious parents declare they have been to a religious service or church-related event in the past 4 weeks with the mother or the father ( $e^{a}$ in our analysis) and this percentage is about $10 \%$ for children of less religious parents ( $e^{b}$ in our analysis). The average fraction of friends who are more religious $\left(q_{i}(g)\right)$ is $60 \%$ for children coming from more religious families and roughly the same percentage for children of less religious parents, with considerable dispersion around these mean values. The remaining control variables do not show noticeable differences between children having more and less religious parents. Roughly, one-fourth of our adolescents are highly performing individuals at school, that is, they had the highest mark in mathematics. The average parental education is higher than high school graduate. About $70 \%$ of our individuals come from a household with two married parents, from a neighborhood of good quality. Protestants are the dominant religious group, followed by the Catholic group. Less than $2 \%$ of our individuals are of various other Christian denominations, and small percentages (smaller than $1 \%$ ) belong to minority religion affiliations (Jewish, Muslim, Buddhist, Hindu). In the remainder of our analysis, we will focus on the transmission of the intensity of religious faith, under the guidance of our theoretical model. Unfortunately, the small sample sizes by religious affiliations (in particular for Jewish, Muslim, and Asian religions) prevent us from running our analysis on the different religious groups separately. We do, however, control for religious affiliation including (child) religious affiliation dummies. ${ }^{15}$

\footnotetext{
${ }^{12}$ This religion-related question is asked in the (in home) parental questionnaire where only one parent is interviewed. The answers to the question "How often have you gone to religious services in the past year" are consistent with answers to other religion-related questions about how important is religion to you and how often she/he prays. The raw correlations are higher than $75 \%$.

${ }^{13}$ The use of four categories of parents' religiosity (instead of two) would leave us with sizes of the sample for each category that are too small to detect statistically significant results.

${ }^{14}$ If one parent only reports no religion, we use the information about the other parent. Children of parents declaring no religion are, however, included when measuring peer religiosity.

${ }^{15}$ We note that in our sample the large majority of children belong to the same religious group as their parents.
} 


\subsection{Identification strategy}

While most of the existing studies on the impact of the social context on individual outcomes measure the social context at a quite aggregate level (neighborhood, classroom, city), ${ }^{16}$ we adopt here a social network approach. As mentioned in the Introduction, contrary to the standard approach where peer effects are conceived as an average intragroup externality that affects identically all the members of a given group (often arbitrary, and at a quite aggregate level), in a network approach this problem does not arise because peers are defined by the smallest unit of analysis, which is the dyad-a twoperson group. It does not solve, however, the problem of the endogenous formation of the group. A credible identification of the effects of peers would be to find variation in the religiosity of peers that is neither related to the child's own unmeasured religious inclinations nor to the (unmeasured components of the) religious inclinations of the parents.

In this paper, we exploit the variation in peer group religiosity that comes from random variation in religiosity in small samples as opposed to variation that can be traced to the parents' choice of which school to send their child or the parents' choice of where to live. When parents choose the school for their children, they are likely to have some sense of the average religiosity of other children that belong to their own religious affiliation and/or own ethnic/racial group in a school. They are, however, unlikely to be aware of how the religiosity varies by grade or gender within a particular school. ${ }^{17}$

We implement an instrumental variables (IV) strategy where we use the average religiosity of other students of the same gender, religious affiliation, and ethnic group in the same grade and school as an instrument for the individual peer group religiosity, and include the following controls in both the first and second stage: religious affiliation dummies, ethnic group dummies, grade dummies, gender, the mean religiosity of other children of the same religious affiliation and ethnic group in the same school as the child in question, a set of dummies for scores in mathematics, parental education level, neighborhood quality, and school dummies. We develop further this IV strategy by adding one more control: the mean religiosity of other children of the same religious affiliation and ethnic group in the same school interacted with grade (as a linear variable). This further control would alleviate worries about parents being aware of trends by grade in religiosity.

\footnotetext{
${ }^{16}$ See, for example, Bisin, Patacchini, Verdier, and Zenou (forthcoming), Oreopoulos (2003), Patacchini and Zenou (2011), and Solon, Page, and Duncan (2000). For an overview of this literature, see Durlauf (2004), Ioannides and Topa (2010), and Ioannides $(2011,2012)$.

${ }^{17}$ Similar assumptions about cohort variation are frequently made in the literature; see, for example, Angrist and Lang (2004), Bifulco, Fletcher, and Ross (2011), Gould, Lavy, and Paserman (2011), Hanushek, Kain, and Rivkin (2002), Hoxby (2000), Lavy and Schlosser (2011), and Black, Devereux, and Salvanes (2013). In this approach, the effect of peers is identified under the assumption that parents and their children do not sort across schools based on differences between the demographic composition of the child's cohort and the average composition of the school.
} 
For each type of parents $r=a, b$ (less religious and more religious parents), our empirical model (equation (14)) becomes

$$
e_{i, t}^{r}=\gamma q_{i, t}+\alpha_{s}+\delta_{c}+\phi_{1} R_{s}+\phi_{2} R_{s} \times c+\sum_{m=1}^{M} \beta_{m}^{r} x_{m, i, t}^{r}+\varepsilon_{i, t},
$$

where $\alpha_{s}$ is a school fixed effect, $\delta_{c}$ is a cohort or grade specific effect, $R_{s}$ denotes the mean religiosity of other children of the same religious affiliation and ethnic group in the same school, and $R_{s} \times c$ captures a school-specific time trend, where $c$ takes the value of 0 for the oldest cohort and increases by 1 for each successive cohort. The set of variables in $x_{m}^{r}$ (for $m=1, \ldots, M$ ) includes the other controls mentioned above (and detailed in Appendix A). The other variables are the same as defined in equation (14).

The idea is to treat the composition of students by grade and gender in a given grade within a school as quasi-random and to isolate this quasi-random variation in the friendship network formation process. The underlying network formation process that supports this strategy is an assortative matching behavioral mechanism where contacts are within individuals who are similar along observable characteristics (most notably grade, gender, religious affiliation, and ethnic group). Then the individual contacts with a given trait are chosen from this population of possible links. They will thus partly depend on the share of individuals with this trait in the population, which is supposed to be exogenous. Indeed, a student of a given grade, gender, religious affiliation, and ethnic group may be simply more likely to form friendships with more religious friends if there are many other students of the same grade, gender, religious affiliation, and ethnic group around who are more religious. For example, if we consider a student who is a male, Catholic, white, and in grade 7, we will take as an instrument for the fraction of his friends who are more religious, the fraction of more religious Catholic white seventh grade males in the school he attends. ${ }^{18}$

Observe that, as explained above, the crucial factor for the dynamics of cultural traits is the presence of cultural distinction versus cultural substitution in the transmission/formation of preferences. As a result, the aim of our empirical analysis is to assess the existence and sign of the relationship between family and social influences. Distinguishing between the importance of different sources of social influence is beyond the purpose of the paper. ${ }^{19}$

\footnotetext{
${ }^{18}$ Fletcher and Ross (2012) model friendship formation and use observable student characteristics to cluster students into groups. Cluster fixed effects are then used in a regression analysis to control for correlated unobservables. Along similar lines, Fletcher, Ross, and Zhang (2013) employ a pair-type fixed effects strategy.

${ }^{19}$ The richness of the AddHealth data, however, provide information that is able to shed some light in this direction. In the language of Manski (1993), social effects can be mainly distinguished between endogenous effects (here friends' parents effort) and contextual effects (friends' characteristics). We have performed our analysis on the subsample of parents having limited contacts with the parents of their children's friends and on the subsample of parents with religiosity above the parents of their children's friends. In both cases, the positive effect of the religiosity of the peers holds true. This evidence points toward the fact that, in our context, endogenous effects are unlikely to explain all social influences. These results are available upon request.
} 


\section{Estimation RESUlts}

\subsection{Results}

Table 1 displays the estimation results of model (15) for all students in our sample (i.e., without distinguishing between children coming from more and less religious parents) in the first three columns. The results are obtained by using the IV strategy described in the previous section. We instrument our measure of peers' religiosity with the average frequency of religious services of children of the same gender, religious affiliation, and ethnic group in the same grade and school. We present the results on our target variable using an increasing set of controls. In column (1), we report the regression with the basic controls while in column (2), we introduce other possibly relevant factors affecting parental effort in transmitting religiosity, namely the number of persons in the household (i.e., family size) and whether the parents are married. Finally, in column (3), we also control for a possible trend in religiosity by grade (as described in the previous section). ${ }^{20}$ We also show the standardized coefficients (beta coefficients), which indicate the change in the dependent variable in terms of standard deviations following a 1 standard deviation increase of the dependent variable. ${ }^{21}$

The first stage $F$ test reveals that the instruments are informative. The estimated coefficient of our target variable, peer religiosity $\left(q_{i}(g)\right.$ in the model), remains roughly unchanged across columns, and shows a positive and significant impact of the social context (i.e., peer effects) on parental effort in the intergenerational transmission of religion. In terms of magnitude, a 1 standard deviation increase of peer religiosity translates into an increase of 0.46 of a standard deviation in parental effort. This means that if on average the friends increase their frequency to religious services from once a month to once a week, parental effort would increase by about $20 \%$.

As a robustness check, Table 1 also shows the results of our analysis when running the same regression on the sample of Christians only (second panel) and when excluding religious schools (third panel). ${ }^{22}$ The results remain basically unchanged. ${ }^{23}$

In Table 2, we display the results by type of parents, keeping the same general structure as in Table $1 .{ }^{24}$ We find a positive and significant impact of the social context (i.e., peer effects) on parental effort for both types of parents. Going back to our theoretical model (Proposition 2), this suggests cultural complementarity for all parents, that

\footnotetext{
${ }^{20}$ The complete list of results, including the first stage, is available in the Appendix B, available in a supplementary file on the journal website, http://qeconomics.org/supp/506/code_and_data.zip.

${ }^{21}$ In short, our empirical model presents two features of note: a large number of fixed effects and an endogenous regressor. The first feature prevents us from using a probit specification, as any probit incorporating a nontrivial number of fixed effects will produce biased results (this is the so-called incidental parameters problem; see Lancaster (2000) for a survey). The second feature prevents us from using the alternative logit specification, as the Chamberlain method of conditional fixed effects does not allow for the presence of endogenous regressors (see, e.g., Chamberlain (1984)). We thus follow the standard practice of using a linear probability model when estimating a binary model with fixed effects and endogenous regressors (see, e.g., Wooldridge (2002, Chapter 15, p. 472) and Lewbel, Dong, and Yang (2012) for a more extensive discussion).

${ }^{22}$ Religious schools are less than $10 \%$ of our sample.

${ }^{23}$ The complete list of results is available in Appendix B.

${ }^{24}$ The complete list of results, including the first stage, is available in Appendix B.
} 
TABLE 1. Religious attendance with parents and peers' religiosity.

\begin{tabular}{|c|c|c|c|c|c|c|c|c|c|}
\hline \multicolumn{10}{|c|}{ Dep. Var. Religious Attendance With Parents $\left(e^{p(a)}\right)$} \\
\hline & \multicolumn{3}{|c|}{ Whole Sample } & \multicolumn{3}{|c|}{ Only Christians } & \multicolumn{3}{|c|}{ Without Religious Schools } \\
\hline & (1) & (2) & (3) & (1) & (2) & (3) & (1) & (2) & (3) \\
\hline Peer religiosity $(q)$ & $\begin{array}{c}3.38^{* * *} \\
(0.79)\end{array}$ & $\begin{array}{c}3.32^{* * *} \\
(0.77)\end{array}$ & $\begin{array}{l}3.31^{* * *} \\
(0.77)\end{array}$ & $\begin{array}{c}3.49^{* * *} \\
(0.84)\end{array}$ & $\begin{array}{c}3.42^{* * *} \\
(0.81)\end{array}$ & $\begin{array}{c}3.42^{* * *} \\
(0.81)\end{array}$ & $\begin{array}{l}4.01^{* * *} \\
(1.18)\end{array}$ & $\begin{array}{l}3.96^{* * *} \\
(1.16)\end{array}$ & $\begin{array}{c}3.90^{* * *} \\
(1.12)\end{array}$ \\
\hline Beta coefficients & 0.44 & 0.45 & 0.46 & 0.49 & 0.49 & 0.49 & 0.52 & 0.54 & 0.58 \\
\hline First stage F-test & 18.271 & 18.592 & 18.701 & 17.376 & 17.701 & 17.689 & 11.671 & 11.792 & 12.241 \\
\hline$p$-value & 0.000 & 0.000 & 0.000 & 0.000 & 0.000 & 0.000 & 0.000 & 0.000 & 0.000 \\
\hline No. observations & 9508 & 9508 & 9508 & 8590 & 8590 & 8590 & 8573 & 8573 & 8573 \\
\hline \multicolumn{10}{|l|}{ Controls } \\
\hline Religious affiliation dummies & yes & yes & yes & yes & yes & yes & yes & yes & yes \\
\hline Ethnicity dummies & yes & yes & yes & yes & yes & yes & yes & yes & yes \\
\hline Grade dummies & yes & yes & yes & yes & yes & yes & yes & yes & yes \\
\hline School fixed effects & yes & yes & yes & yes & yes & yes & yes & yes & yes \\
\hline Family structure variables & no & yes & yes & no & yes & yes & no & yes & yes \\
\hline Mean religiosity & yes & yes & yes & yes & yes & yes & yes & yes & yes \\
\hline Mean religiosity $*$ grade & no & no & yes & no & no & yes & no & no & yes \\
\hline
\end{tabular}

Note: Peer religiosity is the average strength of religion among peers. Precise definitions of variables are given in Table Al. IV estimation results. Peer religiosity is instrumented by the average frequency of religious services of other students of the same gender, religious affiliation, and ethnic group in the same grade and school. Mean religiosity is the average religiosity of other students of the same religious affiliation and ethnic group in the same school constructed with the same variable used to define peer religiosity. Coefficients marked with one (two) [three] asterisks are significant at the 10 (5) [1] percent level. The estimation results for the entire list of controls are given in Tables B1, B3, and B5 in Appendix B. First stage results are given in Tables B2, B4, and B6 in Appendix B. 
TABLE 2. Religious attendance with parents and peers' religiosity.

Dep. Var. Religious Attendance With Parents $\left(e^{p(a)}\right)$

More Religious Parents

Less Religious Parents

(1)

Peer religiosity $(q)$

\section{Beta coefficients}

First stage F-test

p-value

No. observations

Controls

Basic individual controls

Religious affiliation dummies

Ethnicity dummies

Grade dummies

School fixed effects

Family structure variables

Mean religiosity

Mean religiosity $*$ grade

0.42

20.878

0.000

5149

(2)

(3)

$1.93^{* * *}$
$(0.43)$

0.43

20.821

0.000

5149

5149

$1.93^{* * *}$
$(0.43)$

0.43

20.822

0.000

10.801

0.001

3013

3013

(2)

(3)

(1)

$0.81^{* * *}$

(0.26)

$0.80^{* * *}$

(0.26)

0.27

(0.25)

0.27

11.033

11.283

0.000

Note: Peer religiosity is the average strength of religion among peers. A precise list and definitions of variables are given in Tables Al. IV estimation results. Peer religiosity is instrumented by the average frequency of religious services of other students of the same gender, religious affiliation, and ethnic group in the same grade and school. Mean religiosity is the average religiosity of other students of the same religious affiliation and ethnic group in the same school constructed with the same variable used to define peer religiosity. Coefficients marked with one (two) [three] asterisks are significant at the 10 (5) [1] percent level. The estimation results for the entire list of controls are given in Table B7 in Appendix B. First stage results are given in Table B8 in Appendix B.

is, $\frac{\partial e^{r}}{\partial q_{i}(g)}>0$, for $r=a, b$, indicating that $C_{e q}^{r \prime \prime}\left(e^{r}, q_{i}(g)\right)<0$ and $\Delta V^{r}<-C_{e q}^{r \prime \prime}\left(e^{r}, q_{i}(g)\right)$ or $\delta^{r}>\Delta V^{r}$ in the model with specific cost in Section 3.2. Observe that the interpretation of the results are different depending on the parents' religiosity. Indeed, for the more religious parents, the more the child's friends are religious, the more they invest in transmitting religion to their child, that is, the more the child has declared having gone to a religious service or a church-related event in the last 4 weeks with at least one parent. For the less religious parents, the lower is the fraction of religious peers of the child, the less the parents go to a religious service with their child, also indicating cultural complementarity since the transmission is about the less religious trait.

Observe also that even if the sign is positive, the magnitude of the effect is much higher for the more religious parents than for the less religious ones. ${ }^{25}$ Looking at the beta coefficients in Table 2, one can see that the effect is almost two times higher for the more religious parents. In terms of economic mechanism, this suggests that the cost

\footnotetext{
${ }^{25}$ Formal tests on the statistical significance of the difference in magnitudes have been performed and reject the hypothesis that the difference is zero. The value of the $t$ test on the interaction term between (instrumented) peer religiosity and a dummy "more religious parents" in a pooled model with interaction terms rejects the null hypothesis at the $10 \%$ significance level.
} 
function of exerting socialization effort is different between religious and secular parents. This is what we assumed in the theoretical model. Indeed, for the more religious parents, our results show that the more religious friends are around, the lower is their marginal cost of exerting effort. This may indicate that social norms are very strong in the religious environment and that religious parents tend to conform to the behavior of other religious families. For a religious parent, going to church with his/her child is less costly the more the child has religious friends (meaning that the child's religious friends go to church with their parents). For the less religious parents, the effect is much smaller (i.e., $\left.\left|\frac{\partial e^{b}}{\partial q_{i}(g)}\right|<\left|\frac{\partial e^{a}}{\partial q_{i}(g)}\right|\right)$, which may indicate that the cost of going to church with the child is much higher than for the more religious parents.

Our evidence thus shows that, ceteris paribus, (i) the quality of the social context (friends) in terms of religion is an important factor in influencing parental investment in transmitting religion, and (ii) the magnitude of the effect is different for more religious and less religious parents, and is stronger for more religious parents. ${ }^{26}$

\subsection{Evidence on the identification strategy}

Following Bifulco, Fletcher, and Ross (2011), we investigate the validity of our identification strategy by performing two exercises.

First, we produce a table of "balancing tests" for our instrument. If the instrument is unrelated to a variety of predetermined student characteristics, controlling for the fixed effects (and trend) we use in the regression analysis, then the analysis provides evidence supporting the absence of sorting along observable dimensions. Further, if one uses the degree of selection on observables as a guide to the degree of selection on unobservables as suggested by Altonji, Elder, and Tabor (2005), null results on the balancing tests would support the assumption that our model specification identifies variations unrelated to unobservables that determine student outcomes. The results are contained in Table 3. None of the estimated coefficients appears to be significantly different from zero.

The second exercise consists in running placebo tests in which we replace the actual cohort composition measures for each student with measures of the composition of a randomly selected cohort from the same school. If our list of fixed effects controls for unobserved school and student characteristics, then the composition of other cohorts in the same school should not show any effect on student outcomes in these placebo regressions. The results are contained in Table $4 .{ }^{27}$ No evidence of significant correlation is revealed. Thus, this evidence provides further confirmation that unobserved factors that influence within school variation in both cohort composition and student outcomes are not confounding our estimates.

\footnotetext{
${ }^{26}$ We have also examined the sensitivity of our results to a possible measurement error in the definition of the peer group by performing our analysis using a different definition of social networks. Instead of assuming that friendship relationships are symmetric, that is, $g_{i j}=g_{j i}$, we have exploited the direction of nominations. Indeed, our data make it possible to know exactly who nominates whom in a network and we find that $12 \%$ of relationships in our data set are not reciprocal. Thus, instead of constructing undirected network, we have considered directed networks. The qualitative results remain unchanged. They are available upon request.

${ }^{27}$ The complete list of results, including the first stage, is available in Appendix B.
} 
TABLE 3. Balancing tests.

\begin{tabular}{lc}
\hline & Instrument \\
\cline { 2 - 2 } Dep. Var. & $(2)$ \\
\hline PVT test score & 0.0118 \\
& $(0.0088)$ \\
Age (in years) & 0.0087 \\
& $(0.0114)$ \\
Parent years since arrival in U.S. & -0.0007 \\
& $(0.0011)$ \\
Parent born in the U.S. & -0.0094 \\
& $(0.0260)$ \\
Missing parent information & -0.0082 \\
& $(0.0169)$ \\
Log of family income & 0.0066 \\
& $(0.0369)$ \\
Single parent family & -0.0147 \\
& $(0.0206)$ \\
Live w/both biological parents & -0.0228 \\
& $(0.0182)$ \\
Parental education & 0.0032 \\
Number of older siblings & $(0.0030)$ \\
Controls & 0.0029 \\
Religious affiliation dummies & $(0.0062)$ \\
Ethnicity dummies and gender & \\
Grade dummies & yes \\
School fixed effects & yes \\
Mean religiosity & yes \\
Mean religiosity $*$ grade & yes \\
\hline & yes \\
& yes \\
\hline
\end{tabular}

Note: The instrument for peer religiosity is the average frequency of religious services of other children of the same gender, religious affiliation, and ethnic group in the same grade and school. Mean religiosity is the average religiosity of other students of the same religious affiliation and ethnic group in the same school constructed with the same variable used to define peer religiosity. All regressions control for the parents' level of religiosity. Precise definitions of variables are given in Table Al. Coefficients marked with one (two) [three] asterisks are significant at the 10 (5) [1] percent level.

\section{Policy implications}

It is central for economists and sociologists studying the endogenous formation of preferences and of cultural and cognitive traits to be able to distinguish and measure the relative importance, for specific traits, of these different transmission mechanisms: genetic transmission, direct purposeful family socialization, indirect influence of social relationships at large. It is important both for conceptual reasons and as an empirical question. In the present paper, we have focused on the distinction between direct purposeful (parents) and socialization mechanisms (peers). This is crucial because such mechanisms have very different policy implications. 
TABle 4. Placebo tests.

\begin{tabular}{|c|c|c|c|}
\hline \multicolumn{4}{|c|}{ Dep. Var. Religious Attendance With Parents $\left(e^{p(a)}\right)$} \\
\hline & \multicolumn{3}{|c|}{ Whole Sample } \\
\hline & (1) & (2) & (3) \\
\hline Peer religiosity $(q)$ & $\begin{array}{c}0.23 \\
(1.22)\end{array}$ & $\begin{array}{c}0.32 \\
(1.43)\end{array}$ & $\begin{array}{c}0.60 \\
(2.03)\end{array}$ \\
\hline Beta coefficients & 0.05 & 0.07 & 0.13 \\
\hline First stage F-test & 0.161 & 0.143 & 0.132 \\
\hline p-value & 0.555 & 0.654 & 0.733 \\
\hline No. observations & 9381 & 9381 & 9381 \\
\hline \multicolumn{4}{|l|}{ Controls } \\
\hline Religious affiliation dummies & yes & yes & yes \\
\hline Ethnicity dummies & yes & yes & yes \\
\hline Grade dummies & yes & yes & yes \\
\hline School fixed effects & yes & yes & yes \\
\hline Family structure variables & no & yes & yes \\
\hline Mean religiosity & yes & yes & yes \\
\hline Mean religiosity $*$ grade & no & no & yes \\
\hline
\end{tabular}

Note: Peer religiosity is the average strength of religion among peers. Precise definitions of variables are given in Table A1. IV estimation results. Peer religiosity is instrumented by the average frequency of religious services of other students of the same gender, religious affiliation, and ethnic group in the same school with a random assignment of grade. Mean religiosity is the average religiosity of other students of the same religious affiliation and ethnic group in the same school constructed with the same variable used to define peer religiosity. Coefficients marked with one (two) [three] asterisks are significant at the 10 (5) [1] percent level. A complete list of estimation results is given in Tables B9 in Appendix B. First stage results are given in Table B10 in Appendix B.

To illustrate this latter point, even though we do not focus on Muslims in this paper, we consider the implications of our analysis in terms of the transmission of religion for Muslim families. There is a hot debate in Europe about veiling among Muslim women ${ }^{28}$ and whether or not it should be forbidden in public places. ${ }^{29}$ The veiling among Muslim women is clearly an expression of an identity but it is not clear if Muslim women wear veils because their parents pressure them (vertical transmission) ${ }^{30}$ or because these women care about opinions of their community members (horizontal transmission). ${ }^{31}$

\footnotetext{
${ }^{28} \mathrm{By}$ veiling we mean the various types of headcovering and modest forms of dress worn by Muslim women.

${ }^{29}$ Various bans on veiling have been imposed at times in Turkey, Iran, Indonesia, and Tunisia. In 2004, France introduced bans on the Muslim headscarf in public schools. Recently, bans on full face veils have been imposed in Belgium and there have been political moves to further restrict veiling in the Netherlands, Denmark, Italy, Switzerland, and Egypt (see, e.g., Bremner (2010)).

${ }^{30}$ Veiling among Muslim women is often attributed to coercion by fathers and husbands, aimed at increasing their status and control within the family by limiting the outside options of their daughters and wives.

${ }^{31}$ There appear to be strong peer effects on veiling with the opinions of friends, family, and community members influencing the decision to veil (Brenner (1996), Smith-Hefner (2007), Omkar (2007)). Carvalho
} 
Using our model and assuming that the trait to be transmitted is either wearing the veil (trait $a$ ) or not wearing the veil (trait $b$ ), we can disentangle the vertical and the horizontal transmission by testing equation (14). By doing so, we will be able to show if there is cultural complementarity or cultural substitutability. This is crucial because, as shown by Bisin and Verdier $(2000,2001)$ and discussed in Section 3.3, in the long run, under cultural substitution, only cultural heterogeneity will emerge in the society (so that some Muslim women will wear the veil while others will not) while, under cultural complementarity, only cultural homogeneity will prevail in the society (so that either all Muslim women will wear the veil or none of them will wear it). If the objective of the planner is to maximize social mixing so that Muslims and non-Muslims interact with each other, ${ }^{32}$ then the planner would impose a ban on veiling only if there is cultural complementarity. Indeed, in that case, in the long run, there will be either an equilibrium where all Muslims wear the veil $\left(q_{i}^{*}=1\right)$ or an equilibrium where all Muslims do not wear the veil $\left(q_{i}^{*}=0\right)$. This is because of coordination problems and complementarity between the social context (peers) and the parental transmission so that the more parents invest in transmitting the trait $a$ (wearing the veil), the higher is the utility of putting effort in transmitting this trait. How can a ban on the veil help? Imagine that we are in a situation where $0<q_{i}<1$ (which is not an equilibrium under cultural complementarity). Which steady-state equilibrium can the economy reach? If there is no policy, either $q_{i}^{*}=0$ or $q_{i}^{*}=1$ can be reached. By imposing a ban on veiling, we will show that only $q_{i}^{*}=0$ will be an equilibrium. Indeed, such a policy will imply that $\Delta V^{a}$ will be reduced while $\Delta V^{b}$ will increase. This is because $\Delta V^{a} \equiv V^{a a}-V^{a b}>0$ is the expected relative gain in utility for a type $a$ parent of having his/her child wearing the veil while $\Delta V^{b} \equiv V^{b b}-V^{b a}>0$ is the expected relative gain in utility for a type $b$ parent of having his/her child not wearing the veil. When a ban is imposed on the veil, for example, as in France, then (altruistic) type $a$ parents will enjoy less utility of having a child with the veil and type $b$ parents will enjoy more utility of having a child without a veil because it becomes very costly to wear the veil in public places. As a result, type $a$ parents will reduce $e^{a}$, their effort in transmitting trait $a$ (see (7)), while type $b$ parents will increase $e^{b}$, their effort in transmitting trait $b$ (see (8)) so that the $e^{a}-e^{b}$ decreases. Since the dynamics of $q_{i}$ (the fraction of the population that wear the veil, that is, with trait $a$ ) is driven by $e^{a}-e^{b}$ (see Bisin and Verdier (2001)), then the economy will converge to an equilibrium where nobody wears the veil, that is, $q_{i}^{*}=0$. In some sense, this policy will coordinate parents on the equilibrium $q_{i}^{*}=0$.

Obviously, our estimates obtained in the context of U.S. schools do not imply that there is also a cultural complementarity in the case of wearing the islamic veil in France. Our policy discussion should be more considered as a discussion of why the question tackled in our paper could be important for social policy rather than whether it provides a definitive answer to the issue of minorities' sociocultural integration in Europe.

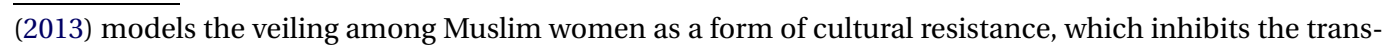
mission of secular values.

${ }^{32}$ Here, we interpret "wearing or not the veil" as a sign of Muslim identity. It has been shown that there is a penalty to be paid in terms of employment for immigrants with a strong identity in Europe (see, e.g., Bisin, Patacchini, Verdier, and Zenou (2011b), Battu and Zenou (2010)). Bisin et al. (2011a) also show that mixing Muslims and non-Muslims increases the ethnic identity of Muslims. 


\section{Conclusion}

We propose a theoretical mechanism of transmission of religion strength based on parents' involvement in religious activities with children and peer effects. Peers, here measured as the friends each student nominates, influence the children's choices in terms of religion strength, not only directly but also indirectly as they affects parents' effort in transmitting their religious trait. The relative importance of these socialization factors (parents and peers) depends on the religiosity of the parents. Using detailed data on friendships between adolescents in American schools, our empirical evidence supports the existence of such an indirect channel. We find that, for religious parents, the higher is the fraction of religious peers of the child, the more parents put effort into transmitting their religiosity, indicating cultural complementarity. For the less religious parents, the lower is the fraction of religious peers of the child, the less the parents go to a religious service with their child, also indicating cultural complementarity since the transmission is about the less religious trait.

\section{References}

Altonji, J. G., T. E. Elder, and C. R. Tabor (2005), "Selection on observed and unobserved variables: Assessing the effectiveness of catholic schools.” Journal of Political Economy, 113, 151-184. [987]

Angrist, J. D. and K. Lang (2004), "Does school integration generate peer effects? Evidence from Boston's Metco program.” American Economic Review, 94, 1613-1634. [982]

Azzi, C. and R. Ehrenberg (1975), "Household allocation of time and church attendance." Journal of Political Economy, 83, 27-56. [972]

Bar-El, R., T. Garcia-Muñoz, S. Neuman, and Y. Tobol (2013), "The evolution of secularization: Cultural transmission, religion and fertility—Theory, simulations and evidence.” Journal of Population Economics, 26, 1129-1174. [972]

Battu, H. and Y. Zenou (2010), “Oppositional identities and employment for ethnic minorities. Evidence from England.” Economic Journal, 120, 52-71. [990]

Bifulco, R., J. M. Fletcher, and S. L. Ross (2011), “The effect of classmate characteristics on post-secondary outcomes: Evidence from the Add Health." American Economic Journal: Economic Policy, 3, 25-53. [971, 982, 987]

Bisin, A., E. Patacchini, T. Verdier, and Y. Zenou (2011a), "Formation and persistence of oppositional identities.” European Economic Review, 55, 1046-1071. [972, 990]

Bisin, A., E. Patacchini, T. Verdier, and Y. Zenou (2011b), "Ethnic identity and labormarket outcomes of immigrants in Europe.” Economic Policy, 26, 57-92. [990]

Bisin, A., E. Patacchini, T. Verdier, and Y. Zenou (forthcoming), "Bend it like Beckham: Ethnic identity and integration.” European Economic Review. [982] 
Bisin, A., G. Topa, and T. Verdier (2004), "Religious intermarriage and socialization in the United States.” Journal of Political Economy, 112, 615-664. [970, 972]

Bisin, A. and T. Verdier (1998), "On the cultural transmission of preferences for social status.” Journal of Public Economics, 70, 75-97. [972]

Bisin, A. and T. Verdier (2000), "Beyond the melting pot: Cultural transmission, marriage, and the evolution of ethnic and religious traits." Quarterly Journal of Economics, 115, 955-988. [970, 971, 972, 973, 974, 978, 990]

Bisin, A. and T. Verdier (2001), "The economics of cultural transmission and the dynamics of preferences.” Journal of Economic Theory, 97, 298-319. [970, 971, 973, 974, 978, 990]

Bisin, A. and T. Verdier (2011), "The economics of cultural transmission and socialization.” In Handbook of Social Economics (J. Benhabib, A. Bisin, and M. O. Jackson, eds.), 339-416, Elsevier Science, Amsterdam. [971]

Black, S. E., P. J. Devereux, and K. G. Salvanes (2013), "Under pressure? The effect of peers on outcomes of young adults.” Journal of Labor Economics, 31, 119-153. [982]

Botticini, M. and Z. Eckstein (2005), “Jewish occupational selection: Education, restrictions, or minorities?” Journal of Economic History, 65, 922-948. [972]

Botticini, M. and Z. Eckstein (2007), "From farmers to merchants, conversions and diaspora: Human capital and Jewish history." Journal of the European Economic Association, 5, 885-926. [972]

Boyd, R. and P. J. Richerson (1985), Culture and the Evolutionary Process. University of Chicago Press, Chicago. [970]

Brañas-Garza, P. and S. Neuman (2007), "Parental religiosity and daughters' fertility: The case of Catholics in southern Europe.” Review of Economics of the Household, 5, 305-327. [972]

Bremner, C. (2010), "Nicolas Sarkozy backs a ban on the full Muslim veil.” The Times (26 January). [989]

Brenner, S. (1996), "Reconstructing self and society: Javanese Muslim women and the veil.” American Ethnologist, 23, 673-697. [989]

Carvalho, J.-P. (2013), “Veiling.” Quarterly Journal of Economics, 128, 337-370. [989, 990]

Cavalli-Sforza, L. L. and M. W. Feldman (1981), Cultural Transmission and Evolution. A Quantitative Approach. Princeton University Press, Princeton. [970]

Chamberlain, G. (1984), "Panel data.” In Handbook of Econometrics, Vol. 2 (Z. Griliches and M. D. Intriligator, eds.), 1247-1318, Elsevier, Amsterdam. [984]

Clark, C. A. and A. Worthington (1987), "Family variables affecting the transmission of religious values from parents to adolescents: A review.” Family Perspective, 21, 1-21. [969] 
Cohen-Zada, D. (2006), "Preserving religious identity through education: Economic analysis and evidence from the US.” Journal of Urban Economics, 60, 372-398. [972]

Durlauf, S. E. (2004), “Neighborhood effects.” In Handbook of Regional and Urban Economics, Vol. 4 (J. V. Henderson and J.-F. Thisse, eds.), 2173-2242, Elsevier Science, Amsterdam. [982]

Fletcher, J. M. and S. L. Ross (2012), "Estimating the effects of friendship networks on health behaviors of adolescents.” NBER Working Paper 18253. [983]

Fletcher, J. M., S. L. Ross, and Y. Zhang (2013), “The determinants and consequences of friendship composition.” NBER Working Paper 19215. [983]

Francois, P. (2002), Social Capital and Economic Development. Routledge, London. [972]

Gould, E. D., V. Lavy, and D. Paserman (2011), "Sixty years after the magic carpet ride: The long-run effect of the early childhood environment on social and economic outcomes." Review of Ecoconomic Studies, 78, 938-973. [982]

Hanushek, E. A., J. F. Kain, and S. G. Rivkin (2002), "Inferring program effects for special populations: Does special education raise achievement for students with disabilities?" Review of Economics and Statistics, 84, 584-599. [982]

Hauk, E. and M. Sáez-Martí (2002), “On the cultural transmission of corruption.” Journal of Economic Theory, 107, 311-335. [972]

Hayes, B. C. and Y. Pittelkow (1993), "Religious belief, transmission, and the family: An Australian study." Journal of Marriage and the Family, 55, 755-766. [969, 972]

Hoge, D. R., G. H. Petrillo, and E. I. Smith (1982), “Transmission of religious and social values from parents to teenage children." Journal of Marriage and the Family, 44, 569580. [969, 972]

Hoxby, C. (2000), "Peer effects in the classroom: Learning from gender and race variation.” NBER Working Paper 7867. [971, 982]

Iannaccone, L. R. (1990), “Religious practice: A human capital approach.” Journal for the Scientific Study of Religion, 29, 297-314. [972]

Iannaccone, L. R. (1998), "Introduction to the economics of religion.” Journal of Economic Literature, 36, 1465-1496. [969]

Ioannides, Y. M. (2011), “Neighborhood effects and housing.” In Handbook of Social Economics (J. Benhabib, A. Bisin, and M. O. Jackson, eds.), 1281-1340, Elsevier Science, Amsterdam. [982]

Ioannides, Y. M. (2012), From Neighborhoods to Nations: The Economics of Social Interactions. Princeton University Press, Princeton. [982]

Ioannides, Y. M. and G. Topa (2010), "Neighborhood effects: Accomplishments and looking beyond them.” Journal of Regional Science, 50, 343-362. [982] 
Jackson, M. O. (2014), “Networks in the understanding of economic behaviors.” Journal of Economic Perspectives, 28, 3-22. [970]

Jellal, M. and F. Wolff (2002), “Cultural evolutionary altruism: Theory and evidence.” European Journal of Political Economy, 18, 241-262. [972]

Lancaster, T. (2000), “The incidental parameter problem since 1948.” Journal of Econometrics, 95, 391-413. [984]

Lavy, V. and A. Schlosser (2011), "Mechanisms and impacts of gender peer effects at school.” American Economic Journal: Applied Economics, 3, 1-33. [971, 982]

Lehrer, E. L. (2008), “The role of religion in economic and demographic behavior in the United States: A review of the recent literature.” IZA Discussion Paper 3541. [969]

Lewbel, A., Y. Dong, and T. T. Yang (2012), "Comparing features of convenient estimators for binary choice models with endogenous regressors." Canadian Journal of Economics, 45, 809-829. [984]

Manski, C. F. (1993), “Identification of endogenous effects: The reflection problem.” Review of Economic Studies, 60, 531-542. [983]

Neuman, S. (1986), "Religious observance within a human capital framework: Theory and applications.” Applied Economics, 18, 1193-1202. [972]

Olcina, G. and C. Penarrubia (2004), "Hold-up and intergenerational transmission of preferences.” Journal of Economic Behavior and Organization, 54, 111-132. [972]

Olivier, J., M. Thoenig, and T. Verdier (2008), “Globalization and the dynamics of cultural identity.” Journal of International Economics, 76, 356-370. [972]

Omkar, K. (2007), Between Being and Believing: Understanding Veiling Amongst British Muslim Women. Master's thesis, Department of Sociology, University of Oxford. [989]

Oreopoulos, P. (2003), “The long-run consequences of living in a poor neighborhood.” Quarterly Journal of Economics, 4, 1533-1575. [982]

Ozorak, E. W. (1989), "Social and cognitive influences on the development of religious beliefs and commitment in adolescence." Journal for the Scientific Study of Religion, 28, 448-463. [969, 972]

Patacchini, E. and Y. Zenou (2011), "Neighborhood effects and parental involvement in the intergenerational transmission of education." Journal of Regional Science, 51, 9871013. [972, 982]

Sáez-Martí, M. and Y. Zenou (2012), “Cultural transmission and discrimination.” Journal of Urban Economics, 72, 137-146. [972]

Smith-Hefner, N. (2007), "Javanese women and the veil in post-Soeharto Indonesia." Journal of Asian Studies, 66, 389-420. [989]

Solon, G., M. E. Page, and G. J. Duncan (2000), “Correlations between neighboring children in their subsequent educational attainment." Review of Economics and Statistics, 82, 383-392. [982] 
Thomson, E., S. McLanahan, and R. B. Curtin (1992), "Family structure, gender, and parental socialization." Journal of Marriage and the Family, 54, 368-378. [969, 972]

Wooldridge, J. M. (2002), Econometric Analysis of Cross Section and Panel Data. MIT Press, Cambridge, MA. [984]

Co-editor Petra E. Todd handled this manuscript.

Submitted October, 2014. Final version accepted December, 2015. 